\title{
Improving the Life Service of Fe-34Mn-10Al-0.76C Tidal Turbine Blades Using Variable PMF
}

\author{
Eisa A. Almeshaiei ${ }^{1}$, Lubanah Ahmad $^{2} \&$ Ibrahim Elgarhi $^{3}$ \\ ${ }^{1}$ Collage of Technological Studies, Public Authority for Applied Education and Training, Kuwait \\ ${ }^{2}$ Jordan University of Science and Technology, Mechanical Engineering Department, Jordan \\ ${ }^{3}$ MSc Alexandria University, Faculty of Engineering, Mechanical engineering Department, Egypt \\ Correspondence: Eisa A. Almeshaiei, Collage of Technological Studies, Public Authority for Applied Education \\ and Training, Kuwait. E-mail: ea.meshaieie@paet edu.kw
}

Received: February 21, 2021

Accepted: March 30, 2021

Online Published: March 2, 2022

doi:10.5539/jmsr.v11n1p40

URL: https://doi.org/10.5539/jmsr.v11n1p40

\begin{abstract}
This paper studied the effect of increasing pulsed magnetic field (PMF) voltage during treating a Fe-34Mn-10Al-0.76C steel alloy used in fabricating a blade to be installed in a tidal turbine on its fatigue lifetime. Fatigue strength for each sample treated using PMF voltages $(0,100$ and $160 \mathrm{~V})$ had been investigated experimentally to plot their S-N curves while fatigue lifetime of the tidal turbine had been predicted using mathematical model established by a MATLAB code. The cyclic loadings affect the studied turbine were rearranged using Rainflow algorithm. Results of the study showed that, the blade made of Fe-34Mn-10Al-0.76C steel alloy and treated using PMF $100 \mathrm{v}$ had achieved the highest fatigue resistance. The aforementioned fact had investigated based on comparing among the three specimens under the same conditions. For each specimen, the effect of the tidal turbine operation period according to fatigue lifetime been examined as well and it was investigated that, increasing number of operation hours resulted in a drastic reduction in the turbine's fatigue life of the turbine.
\end{abstract}

Keywords: Fe-34Mn-10Al-0.76C steel alloy, MATLAB, Pulsed Magnetic Field (PMF), rainflow algorithm, SEM

\section{Background}

Tidal energy had paid attention last few years, because it estimated to be able of sharing a high percentage of the global electrical power consumption if it had harvested efficiently. Tidal energy techniques had developed noticeably last few years, which resulted in paying a higher attention by both of the public and private investors. As a result, the electrical power generation rate from marine turbines is highly increased as it had compared in the following figure according to the continents. It is clear that, the green electricity generated from tidal energy is doubled within the period of 2009 to 2018 (Milad et al., 2019) and there are different predictions that refer to the possibility of increasing this production rate in the coming few years due to main reasons that are subjected to economy, fossil fuel depletion and environment. In other words, satisfying the recently seen electrical power demand of the world resulted in increasing the fossil fuels' dependency resulting in different negative consequences. For example, generating electricity in conventional power stations relying on firing fossil fuels resulted in emitting such toxic gases that are the main reason of the recently seen climate changes, greenhouse gases, low quality of air, low purity of water, high toxicity levels of the soil, environmental impacts on the wildlife and the global warming. In addition, the higher dependency of fossil fuels resulted in increasing the pricing rate of the unit energy that deprives such regions from being supplied by electricity as the developing countries. Moreover, construction of conventional power stations is extremely expensive and require very long periods. Fossil fuels reduction is one of the most important issues should be taken into consideration when deciding increasing renewable energy dependency as well, which grantees the coming generations to live and continue the recently seen technological and industrial revolutions (Stephens et al., 2010), (Browne et al., 2012) and (Baige et al., 2017). 


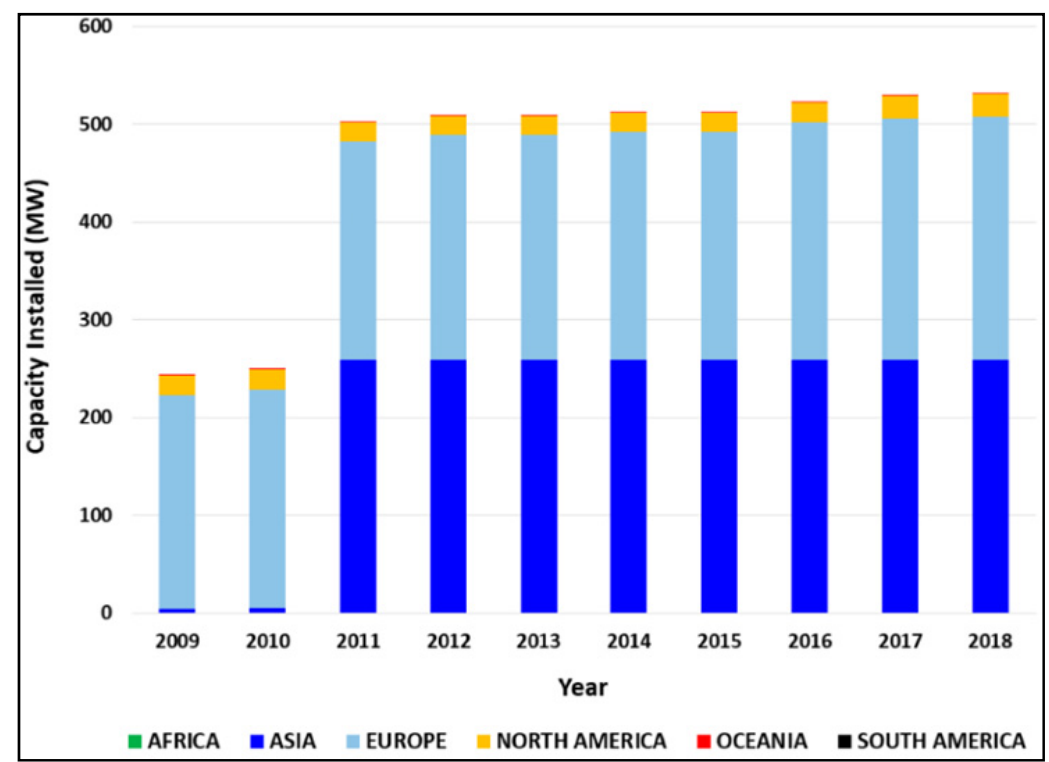

Figure 1. Comparison among the electricity power generation from tidal energies from 2009 to 2018 according to continents (Milad et al., 2019)

Tidal energy characterized by its high availability, which encourages decision makers to increase its dependency in generating sustainable electrical energy in case of it investigated to be feasible according to its economy. According to data provided by IRENA, tidal energy is able to provide promising sustainability level due to its very high potential. The following figure represents the tidal power distribution in the globe and it is clear that; there is a high potential of energy that would share a high percentage of the electricity consumed by the globe if it is harvested with a high-energy conversion efficiency (IRENA, 2020).

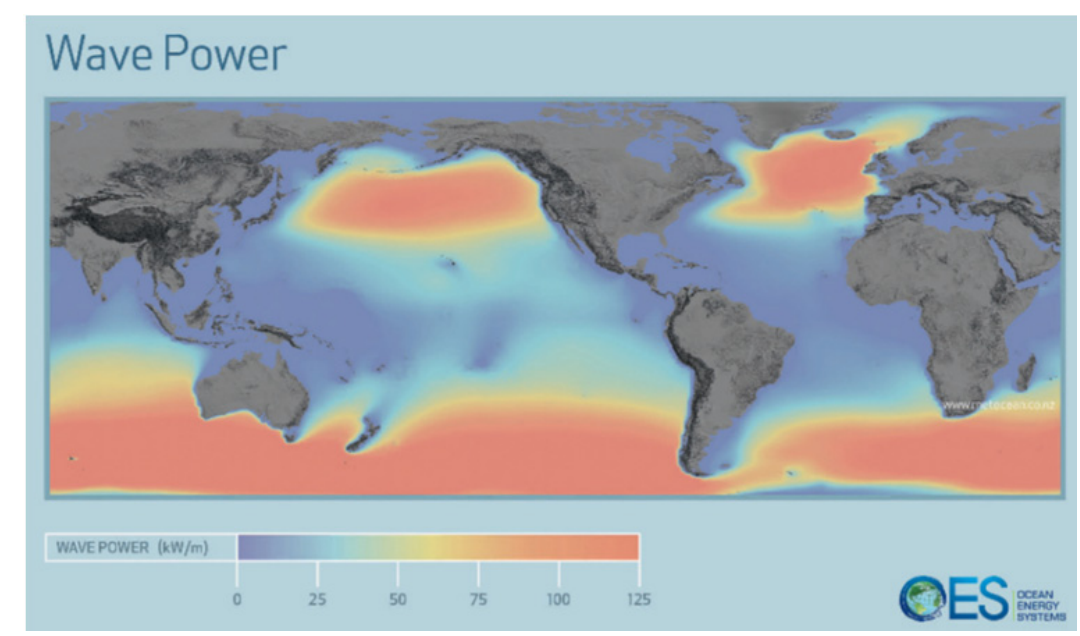

Figure 2. Tidal power distribution around the world (IRENA, 2020)

Generally, the energy conversion efficiency of a tidal turbine is highly influenced by different parameters that are extremely complex which to consider in a single study. Researchers suggested either studying these parameters individually or neglecting the less influencing ones for a purpose of reducing the study's complexity level. Tidal turbine's design, installation, operation and maintenance are not simple and require a deep recognition of the operating factors and environmental conditions as well as the effect of the blade design, material and configuration on each stage. For a clearer vision, a design engineer should be aware of the main source of failures and shutdown of tidal turbines to avoid them during the design and manufacturing stages that result in avoiding such unnecessary 
economic losses. For example, the following Figure (3) shows the data collected from different countries that represent the breakdown had assigned for different tidal turbines' applications. It is clear that, offshore tidal turbines which estimated to fail by a higher possibility if it had compared with either nearshore or onshore tidal turbines. However, the attention paid to the offshore tidal turbines that subjected to the higher electrical power output to be achieved, which translated into a higher economic and environmental gain.

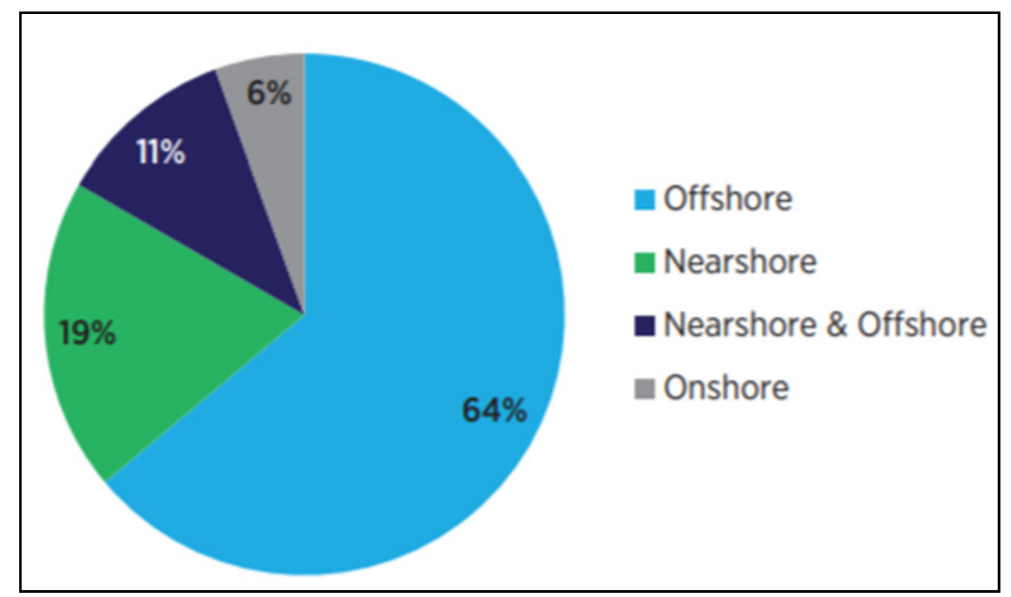

Figure 3. Tidal turbines Breakdown possibility (\%) according to their application (IRENA, 2020)

Failure sources of a tidal turbine are many and they related to the blade material and design in addition to the turbine type and configuration. Moreover, the possibility of failure of a tidal turbine that subjected to the tough environmental conditions under seawater, which should study in details for a purpose of investigating the lifespan of a turbine. The attention paid to attain an accurate prediction of a tidal turbine service lifetime had related to its very high initial and running costs, which assumed as being the most challenging issue that restricts widening its dependency and prevents decision makers from investing this promising energy sector. Fatigue failure is one of the most common fracture forms that results in breaking a tidal turbine operation leading to reducing its output as well as increasing its running cost. Researchers mainly investigate fatigue stress of such a tidal turbine during its design stage using different techniques. Fatigue failure can be investigated based on predictions or experimental studies. Factually, simulating fatigue failure mechanism is complex and subjected to different parameters that are not stable at all due to seasonal fluctuations (Gant \& Stallard ., 2008). In addition, experimental investigation of the fatigue stress of such a blade is expensive and require specially manufactured instrumentations (Milne, Ian. , 2014).

In addition to the environmental issues and operating surroundings influence on the performance provided by a tidal turbine, the blade design and material considered as a key matter of attaining a high lifespan as well. In general, the material selection process of a blade assessed to be a vital step that should paid a significant attention to achieve a high accuracy regarding the predictions of the tidal turbine performance. Manufacturing a blade from such a material that categorized by a high mechanical properties, high density and high surface roughness would assure achieving a high level of mechanical safety while reducing its energy conversion efficiency. Alternatively, selecting such a material that is characterized by low mechanical properties, low density and low surface roughness would result in achieving an optimum operation with very low safety level leading to undesirable consequences during its operation. Hence, the material and design of a blade as well as the configuration of the turbine (its type) which should optimized based on the expected operating and environmental conditions (Angelo et al., 2016) and (Zhu et al., 2020).

\subsection{Environmental Conditions and Impacts}

The performance of a tidal turbine predicted to be highly affected by the environmental situations under the seabed. The major environmental concern with tidal energy converters had related to the blade strike and death of marine creatures due to high velocities of water. In addition, high water velocity escalates the chances of marine creatures might pushed next to or via such equipment. Tidal turbines have blades with complex aerofoil cross sectional area and work as per hydrodynamic lift principles, because aerodynamic lift is much more efficient as compared to hydrodynamic drag. The possibility of a marine organism to go through a tidal energy converter is evidently higher 
for tidal barrages than for tidal stream turbines. Since the barrages do not offer any chance for the marine organisms to choose an alternative direction in contrast to wind power generation, the unavailability of extreme speeds help reduce damage caused to devices as well as mortality rates of marine organisms, therefore, a rise in in rotation speed of turbines the higher the death rate observed. Technological advancements such as use of helical turbines allow low rotational velocities, this is essential to reduce or completely avoid death or damage to the turbine. Use of helical turbines with enhanced technology tend to imitate physical configuration of fish and has a large space that can allow several marine creatures to pass through without being killed or damaging parts of the turbine. The counter interaction of a static part of a tidal energy with a marine creature, rarely considered crucial, therefore not evaluated. Although this forms a harmful threat to the marine life, and predicted to result in a significant economic loss as well. As most of these impacts resulted in breaking the turbine down then maintained or at least reduces its output (Jha et al., 2016).

Tidal energy turbines are made up of rotating lift devices that the potential of removing kinetic energy from water in motion. The operations of such lift devices with the moving body of water creates pressure differences between both of the blade upstream and downstream as well as the high level of turbulences. The major risks that marine creatures face, especially fishes, the risk of colliding with the rotating turbines of turbine energy converters. In addition, instant changes in pressures on both sides of the turbine surfaces swept area has become another big risk for marine organisms. A region of high pressure created on the turbine upstream; this usually followed with a rapid decline in pressure on the lower swept surface area of the turbine. However, the extent of hydrofoil strike is dependent on the size of fish, turbines parameters and the requirements in the geographical site. By establishing the pressure variations that fish subjected to, it is easy to find out the potential risk of harm on them. Just after a drop in pressure, pressure increases rapidly until it reaches the atmospheric pressure inside the draft tube and the tail waters. Such rapid changes in pressure cause injury to the fish or even cause death due to the instant volume variations in their swim bladder as proportionate to Boyles Law. Damage levels in fish caused by counter impacts with a tidal wave or turbine is greatly dependent on the properties of the equipment. The location of the equipment is crucial in protecting the fish from the risk of collision. Together with the type of swim bladder, adaptability of marine creatures to high pressure just before passage could possess some impact on pressure caused deaths (G. F. Cada, 1997).

Turbulence is not a crucial issue as compared to pressure deviations during turbine passage. The two main factors that contribute to the survival rate of fish include turbine dimensions (this can cause loss of direction and dizziness based on the structural size of fish), shear force (it causes tearing and deformation). Disorientation is a crucial challenge for creatures going through a typical hydroelectric turbine since it can lead the marine creature to counter the runner or the draft tube walls. Installation of a tidal energy converter can generate a lot of turbulence especially from the lower side of the rotor. Tidal channels contain great amounts of turbulent water, the turbulence generated by the waters and the rotor converted to heat. If the marine creatures do not feel the effect of blade strike, turbulence is less likely to cause death, as per the observed changes at the typical hydroelectric turbines. It is clear that that size of marine creatures is important in determining the extent of damage caused by turbulence. Small sized marine creatures end to be more prone to damage as compared to the larger ones. Therefore, turbulence deliberated as an indirect cause of death among marine creatures who lose their sense of direction. The estimated death rate of copepods is around $7.7 \%$ on the exterior surfaces of the wake and a corresponding $14.3 \%$ on the interior of the wake.an increase in the intensity of turbulence caused an increased death of copepods. Every turbine energy converter must analyzed on its turbulence production potentials together with their impact on the existing ecological zones (G. F. Cada, 1997).

With the numerous benefits of offshore renewable sources of energy, high concerns have brought forward on the generation of electromagnetic fields and acoustic output that affect marine creatures; this is because the devices had planted in deep waters. Therefore, the acoustic effects can be much greater than those generated by wind energy can. Depending on the number of oscillations per second and the amplitude of the acoustic wave produced by tidal device, acoustic noise can have different impacts on marine creatures especially dolphins and whales. Little research has done on the minimum acoustic value for marine creatures; however, a research established that cod would sustain long-term damages to hearing minimum value from noises higher than $180 \mathrm{~dB}$. In addition, noise levels can be raised by ships, however the noise from tidal energy converter is constant while that from a ship is temporary (Lossent et al., 2018).

\subsection{Fatigue Failure}

Fatigue deliberated as being one of the most common types of failure in tidal turbines, which mainly generated due to the oscillating hydrodynamic forces applied on the blade. Generally, fatigue expected to reduce the energy conversion efficiency of a tidal turbine, increasing its running cost and breaking it down in case of the mechanical 
fracture takes place. In addition, surface cracks generated due to fatigue estimated to result in reducing the reliability of the turbine as well as its mechanical safety (Val et al., 2012).

Figure (4) In case of applying a hydrodynamic force with such magnitude that depends on the environmental conditions that fluctuate over the year, the blade structure then deflected due to the generated mechanical stress. Unfortunately, repeating this hydrodynamic force with different magnitudes and directions resulted in fatigue stress, which considered as being one of the most important parameters that refer to the lifespan of a tidal turbine (Murray et al., 2016).

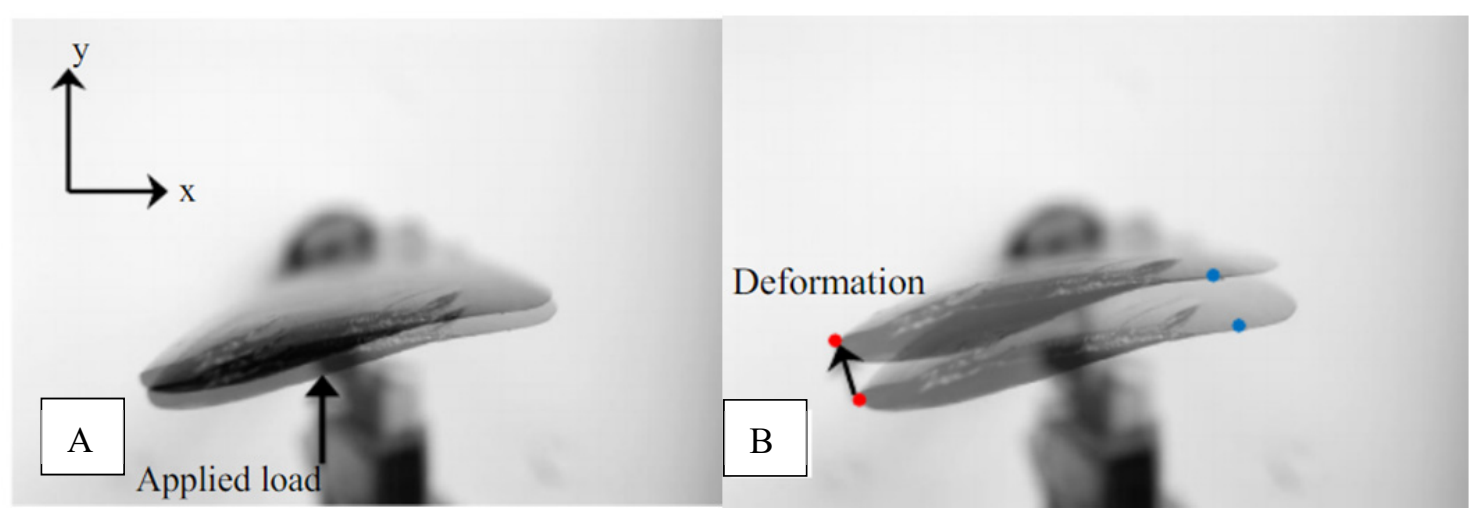

Figure 4. Effect of applying a hydrodynamic force on the blade tip (Murray et al., 2016)

Fatigue stress refers to the ability of such a material to withstand against oscillating loads for a certain number of cycles. Fatigue stress is one of the most important mechanical properties should be identified for the material used in manufacturing an engineering application. There are four common stages of fatigue mechanism, those represented in the following Figure (5) (Limon et al., 2016). In this study's point of interest referring to, it is obvious that; the performance of a tidal turbine is predicted to be related to the fatigue stage. In other words, at the second stage of fatigue failure (Small crack growth); the blade surface roughness increases due to crack existence leading to increasing wake region formed downstream the blade resulting in decreasing the energy conversion efficiency. Fatigue becomes more dangerous and effects harmfully on the tidal turbine when these surface cracks become larger until reaching the mechanical fracture that may result in operational and economic disastrous consequences (Val et al., 2012).

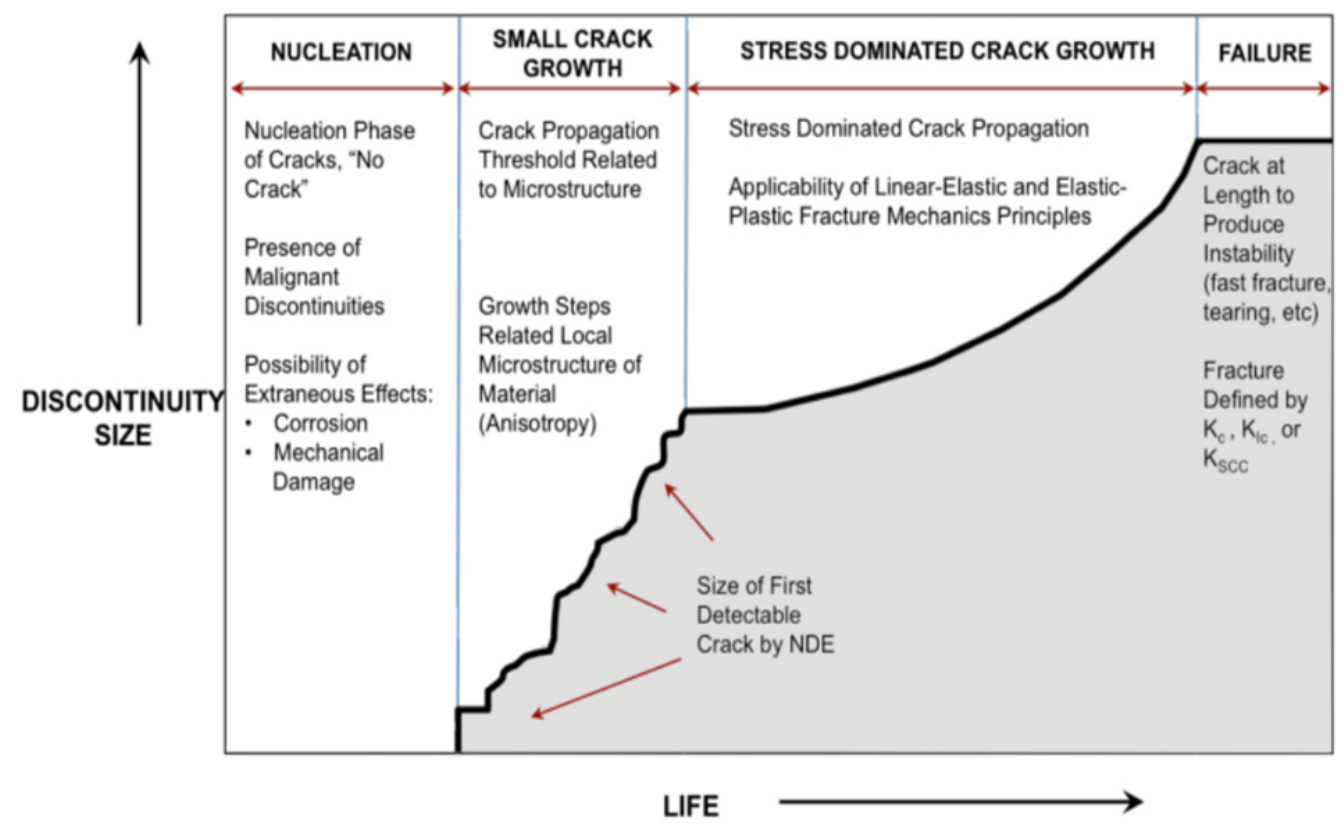

Figure 5. Fatigue failure stages (Limon et al., 2016) 


\section{Blade Materials}

A tidal turbine blade expected to has affected by different parameters that should have recognized in details in order to optimize the performance of the turbine. This should be considered from the design stage of the turbine. For example, the turbulence intensity of the tides varies according to the geographical location of the turbine and the geographical location of the turbine should has decided during studying the turbine feasibility. These decisions help design engineers in selecting a highly performing blade profile and suitable material that is able of providing the required safety level. In addition, the flow velocity of seawater highly influences the magnitude of both the thrust and tangential hydrodynamic forces applied on the blade that are estimated as being the main reason of the fatigue stresses. Tidal turbines designed to be able of serving under tough operating conditions sustainably and for long time as they are expensive and their payback period is long. However, the key issue of achieving the aforementioned desire that subjected to the material selected to satisfy these conditions (Hulse et al., 2011).

The material, which selected based on several parameters in addition to its mechanical performance. As the selected material that characterized by low density to reduce the energy losses during the energy conversion process. This material advantaged by high availability, manufacturability and reliability. As a high availability and manufacturability of this material would help in reducing its cost while the high reliability would enhance its dependency. The selected material should not negatively effect on the environment to avoid reducing the water purity or water and harmfully effect on the wildlife (Jaksic et al., 2017).

Different materials had been provided a promising performance regarding satisfying the optimum performance of a tidal turbine. The significant advancement had achieved in the metallurgical applied science allowed developing such alloys that characterized by unique mechanical, physical, thermal and chemical properties. The low-density steels ( $\mathrm{Fe} \mathrm{Mn} \mathrm{Al} \mathrm{C}$ ) had developed noticeably last few years, their unique performance encouraged researchers to optimize its carbon content to attain a desired mechanical performance. Different alloys had developed by varying the contents percentages. Each alloy investigated to provide a unique performance in such application.

Referring to the concerned alloy (Fe-34Mn-10Al-0.76C), Ferrite (Iron) existence assures achieving a high mechanical performance while magnesium existence helps in enhancing these properties. Aluminum in the studied alloy decreases its density resulting in reducing the manufactured engineering structure's weight. Carbon mainly added to enhance its toughness resulting in increasing the material resistance against impacts and unexpected collisions (Kartikasari et al., 2019).

Not only developing modern materials and alloys had paid the researchers attention, as they developed such techniques that have used in enhancing their mechanical, physical and thermal properties that resulted in maximizing the performance that achieved by an engineering application. In addition, effecting on the steel alloys with magnetic field with a predetermined intensity projected to result in enhancing its mechanical performance. Pulsed magnetic field (PMF) technique showed a promising performance regarding attaining different benefits such as enhancing the material mechanical properties, reducing solidification time and increasing the material dependency regarding satisfying a higher safety level. A study had been applied on a steel alloy showed that, increasing magnetic field intensity resulted in changing the elastic modulus, tensile strength and grain size while it has a low effect on its hardness however, there is such an optimum magnetic field intensity had been investigated, which resulted in maximizing the mechanical performance of the studied material (Andro et al., 2017).

\section{Method}

Referring to the main objective of the proposed paper, which tends to investigate the effect of PMF voltages on the fatigue lifetime of a tidal turbine for different blade thicknesses, it has decided to divide the scientific approaches into sequential steps. The research done with several presumptions and scientific techniques. These steps, which represented in details as follow;

The decision taken to assume that, the examined tidal turbine is horizontal and constructed from six identical blades as shown in Figure (6). 


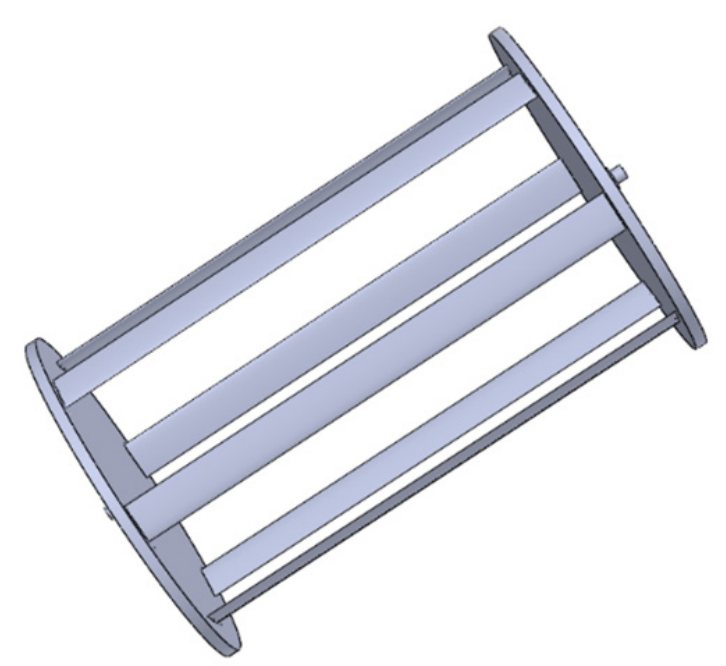

Figure 6. 3D illustration of a tidal blade

The detailed technical description of the 3D modelled turbine is shown in Table (1). The distance from the stanchion centre to the centre of the tidal turbine is $2.5 \mathrm{~m}$ while the stanchion diameter is $1.5 \mathrm{~m}$. The 3D fluid domain had decided to have a length, width and height of $150 \mathrm{~m}, 50 \mathrm{~m}$ and $50 \mathrm{~m}$ respectively.

Table 1. The specifications of the proposed model

\begin{tabular}{|l|r|l|}
\hline \multicolumn{1}{|c|}{ Parameter } & Value & \multicolumn{1}{c|}{ Units } \\
\hline Turbine Diameter & 10000 & $\mathrm{~mm}$ \\
\hline Hub Diameter & 1788.46 & $\mathrm{~mm}$ \\
\hline Blade Pitch & 6 & $\mathrm{Deg}$ \\
\hline $\begin{array}{l}\text { Distance From Centre of } \\
\text { Turbine Blade to Centre of } \\
\text { Stanchion }\end{array}$ & 2500 & $\mathrm{~mm}$ \\
\hline Stanchion Diameter & 1500 & $\mathrm{~mm}$ \\
\hline Fluid Domain (Box) & 150000 & $\mathrm{~mm}$ \\
\hline Length & 50000 & $\mathrm{~mm}$ \\
\hline Width & 50000 & $\mathrm{~mm}$ \\
\hline Height & & \\
\hline MRF Domain (Cylinder) & 4500 & $\mathrm{~mm}$ \\
\hline Depth & 6000 & $\mathrm{~mm}$ \\
\hline Radius & 3.61 & \\
\hline TSR & 3.086 & $\mathrm{~m} / \mathrm{s}$ \\
\hline V & 5 & $\mathrm{~m}$ \\
\hline TurbRad & 2.228092 & $\mathrm{rad} / \mathrm{s}$ \\
\hline Omega
\end{tabular}

Every blade in the researched horizontal turbine had fabricated from Fe-34Mn-10Al-0.76C steel alloy that offered greater service lifetime and a high resistance to fatigue and mechanical loading. Every blade selected had subjected to different PMF (pulsed magnetic field) voltages, which are $0 \mathrm{~V}, 100 \mathrm{~V}$ and $160 \mathrm{~V}$.

Fatigue resistance of the pulsed magnetic field refined strength Fe-34Mn-10Al-0.76C composite sample that meant to examine experimentally for the fatigue strength test. The testing machine suggests employing a control sample that is illustrates geometrically as shown in Figures (7) and (8). Consequently, illustrates the 
experimentally examined sample. The machine recommends using a standardized specimen that described geometrically in Figure (11), while Figure (12) shows the experimentally tested specimen.

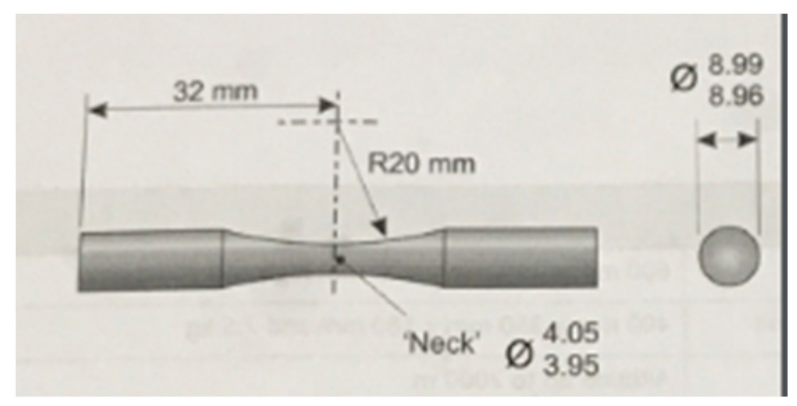

Figure 7. Geometry of the sample to be examined using fatigue test machine

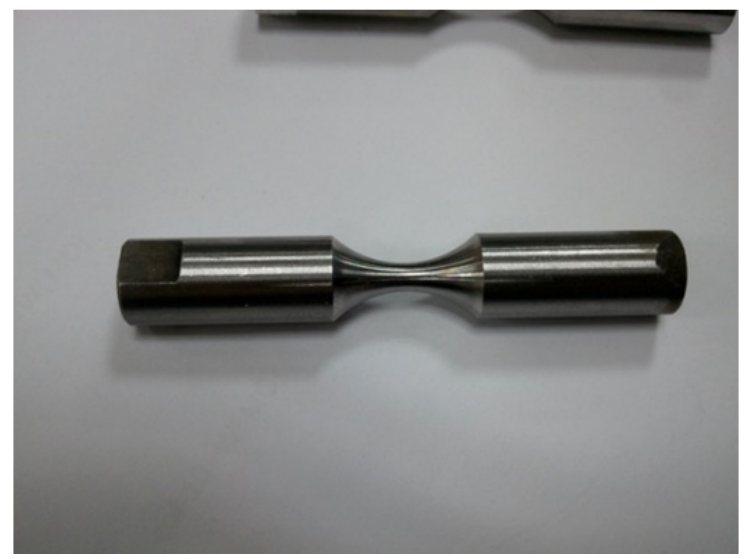

Figure 8. Practical implementation of the specimen to be examined experimentally

The fatigue strength test was determined based on different cyclic loads executed on the sample and enumerating the cycles prior to mechanical failure. This executed many times to attain varying fracture peak points when varying cyclic stresses. The laboratorial outcomes then expressed in an S-N curve of the material to allow the calculation of the $(\mathrm{m})$ value, which is very essential to be determined and estimated to be change due to changing the PMF voltage for fatigue lifespan mathematical prototype meant to be designed.

After the S-N curves have plotted, the (m) values then determined as it had represented in the following Table (2). It then examined that; the lowest $(\mathrm{m})$ value predicted to been achieved for the Fe-34Mn-10Al-0.76C steel composite treated by PMF $100 \mathrm{~V}$. Hence, it is clear that increasing the voltage of the PMF is not vital to assure achieving a higher mechanical performance (fatigue strength) by increasing the PMF voltage continuously. As there is such an optimum voltage should be determined to reduce the running cost of the material treatment process. 
Table 1. PMF voltage effect on the $\mathrm{m}$ values for Fe-34Mn-10Al-0.76C steel composite

\begin{tabular}{ll}
\hline PMF Voltage & $\mathrm{m}$ \\
\hline $0 \mathrm{~V}$ & 5.03 \\
$100 \mathrm{v}$ & 4.86 \\
$160 \mathrm{~V}$ & 4.91 \\
\hline
\end{tabular}

Mathematical equations that describe the fatigue mechanism are complex and need keen following of procedures to ensure that the error percentage in the mathematical prototype is minimized. The major source of complexity is due to the changing intensity of turbulence and the highest peak of a tide over the year, which leads in varying the thrust loadings executed on each tidal turbine blade of the tidal turbine been studied. These fluctuations, which recorded concerning the period and rotation angle of the tidal blade. These constantly changing thrust loads then predicted as the major cause of fatigue, which had earlier looked into keenly in the suggested paper. Such cyclic stress can reach separately or through calculating the mean value of the loadings. With reference to, the collected data that been plotted in a graph as shown in Figure (9), the thrust loadings executed on the three blades greatly changed over time. For a period of 27 seconds, the thrust loadings vary because of fluctuating intensities of turbulence as well as the tidal amplitudes.

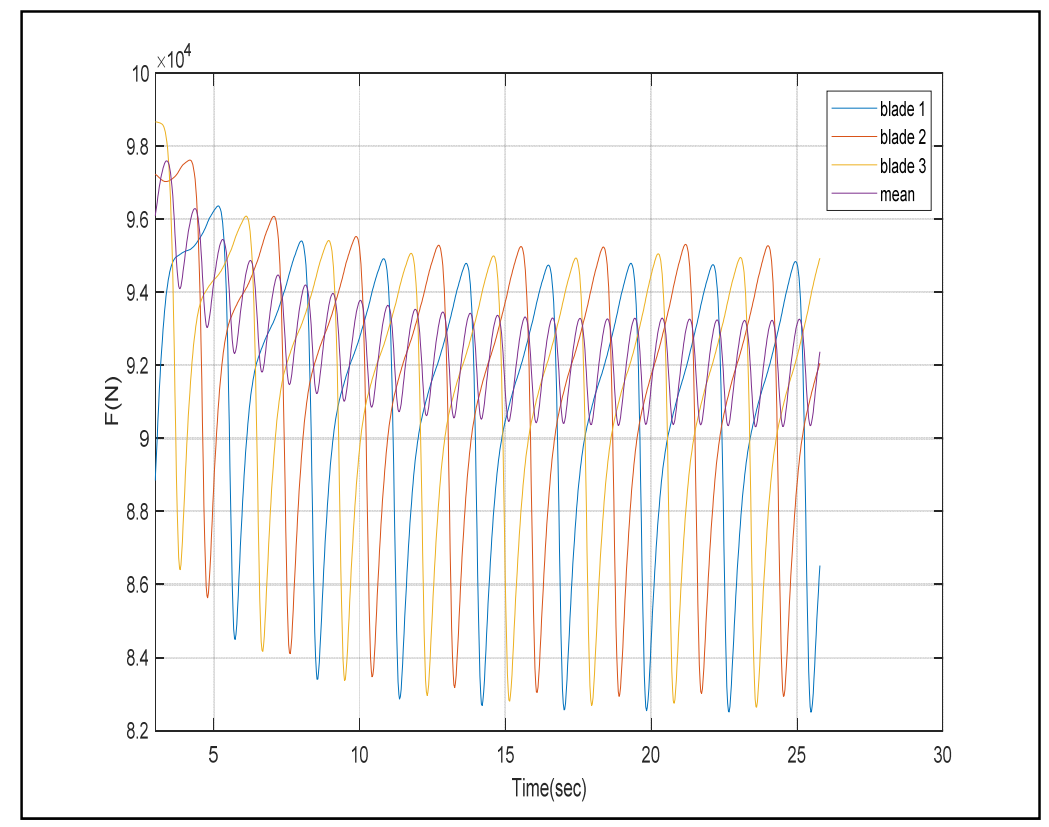

Figure 9. Cyclic stresses executed on the blades over time

Alternatively, the thrust loadings, which predicted to vary about the angle of rotation. Figure (10) illustrates the thrust loadings executed on every blade together with the average thrust load for each rotational angle. 


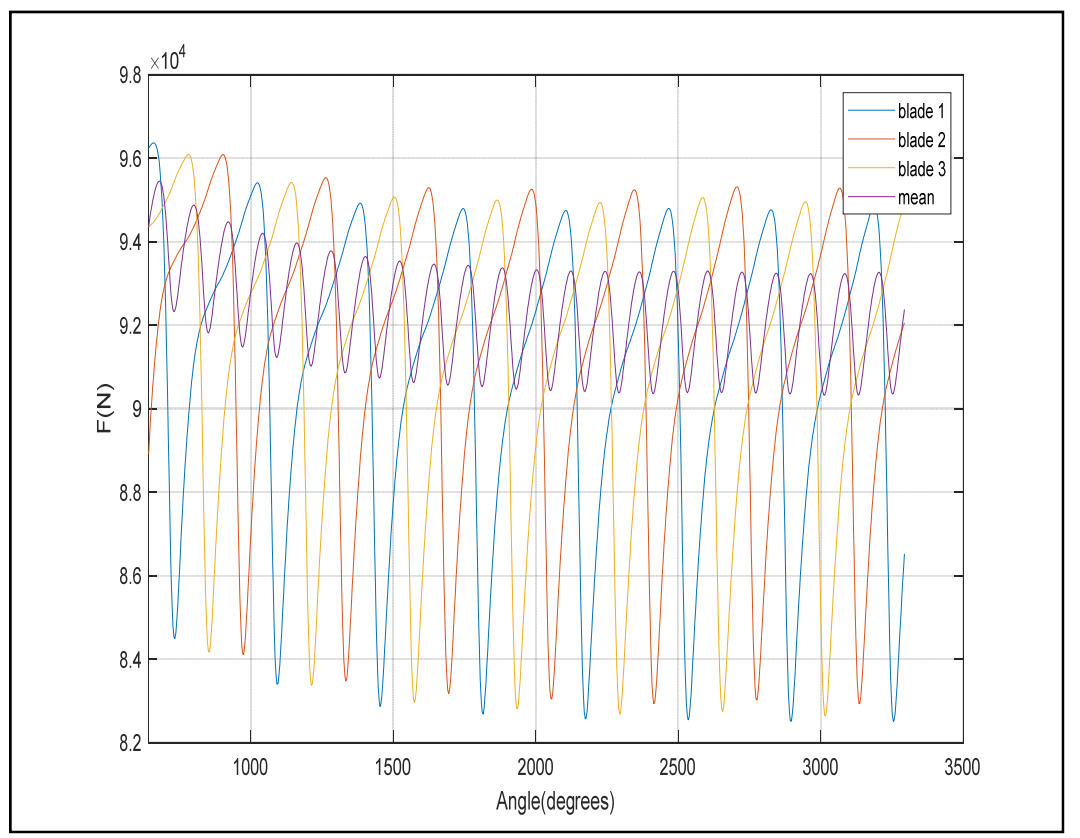

Figure 10. Cyclic stress executed on the blades against blade rotational angles

Therefore, the challenge of lowering the complexity of fatigue mathematical expression is dependent on purifying and rearranging these unstable thrust forces. This can be attained by the Rainflow algorithm. The average thrust forces figures may be rearranged by the Rainflow algorithm function in the MATLAB software. It enables knowing the number of cycles in during a predetermined time (27 seconds) for each cyclic loading, which enables factoring in the consistent values. Figure (11) illustrates the cyclic stress span and the related frequencies.

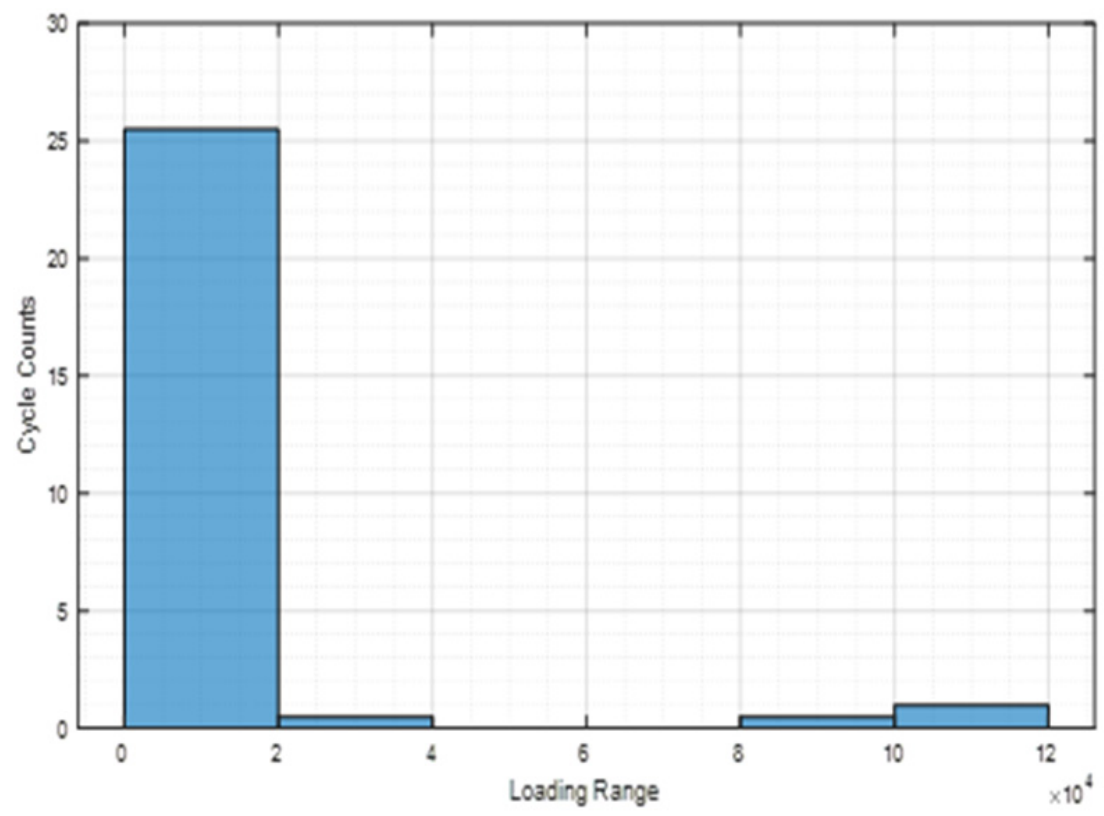

Figure 11. Cyclic loading spans and the number of cycles in a second by the Rainflow algorithm

After the frequency for every cyclic load or stress range (i) was established, the Damage equivalent load (DEL) can estimated as shown in the mathematical equation expresses below. 


$$
D E L=\left(\frac{\sum_{i}\left(l_{i}^{m} * n_{i}\right)}{t}\right)^{m^{-1}}
$$

This mathematical equation intended to describe the DEL used in evaluating the fatigue lifespan of the tidal turbine under research. Where (t) is the blade thickness of the steel alloy subjected to PMF, (li) refers to the time history while $(\mathrm{m})$ refers to the negative inverse gradient of the S-N curve that had shown on the alloy. Previously (m) values had determined experimentally and it investigated that, changing the PMF voltages of the treated steel alloy resulted in changing it. The following Figure (12) shows the relationship between the varying PMF voltages and the $(\mathrm{m})$ values. Hence, fatigue resistance estimated then changed due to changing the PMF voltages.

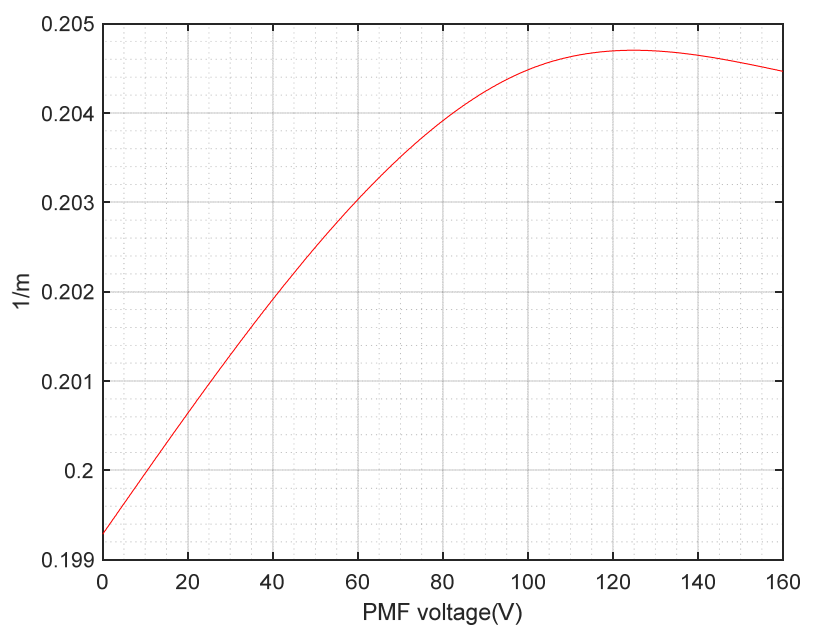

Figure 12. PMF voltage effect on the m values for Fe-34Mn-10Al-0.76C steel composite

$\left(n_{i}\right)$ Describes the number of cycles for every cyclic stress range. It is important to state that, fluctuating the PMF voltage that a material exposed to may lead to a change in the S-N curve of the alloy thus a change in the $(\mathrm{m})$ value. Therefore, this research is applicable specifically for Fe-34Mn-10Al-0.76C alloys that have refined by PMF at different voltages.

Damage equivalent load (DEL) values been used in finding the fatigue lifespan of the tidal blade using the two mathematical equations expressed below.

$$
\begin{aligned}
\text { S. E. } \mathrm{L}_{\mathrm{i}} & =\frac{\text { D. E. } \mathrm{L}}{A} \\
\text { lifetim } \mathrm{e}_{\mathrm{i}} & =\left(\frac{\text { S. E. } \mathrm{L}_{\mathrm{i}}}{\mathrm{S}_{\mathrm{f}}}\right)^{-\mathrm{m}}
\end{aligned}
$$

Given that;

Where, $S_{f}=$ fatigue strength (which is the most essential feature of the alloy)

The research, which meant to look into several parameters that presumed to be greatly affecting the fatigue lifespan of the mathematically studied tidal turbine. Some of these factors is the number of hours that the tidal turbine is operating. The working hours of the tidal blade greatly influences its lifespan and output.

\section{Results}

The pulsed magnetic field (PMF) refined the Fe-34Mn-10Al-0.76C composite microstructure, which had earlier scanned via SEM and its internal structure. This predicted to result in a noticeable change in the material's properties. Figures 13,14 and 15 represent the microstructure change of the studied alloy due to changing the PMF voltage. 


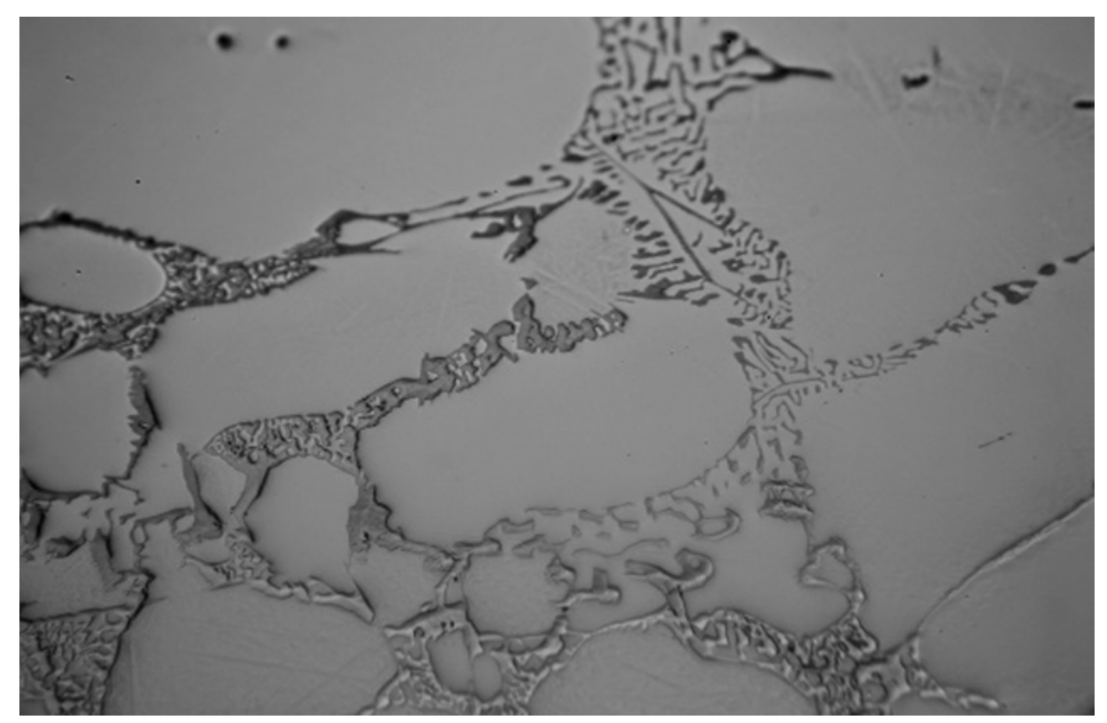

Figure 13. SEM image of Fe-34Mn-10Al-0.76C composite at PMF $=0 \mathrm{v}(\mathrm{x} 400)$

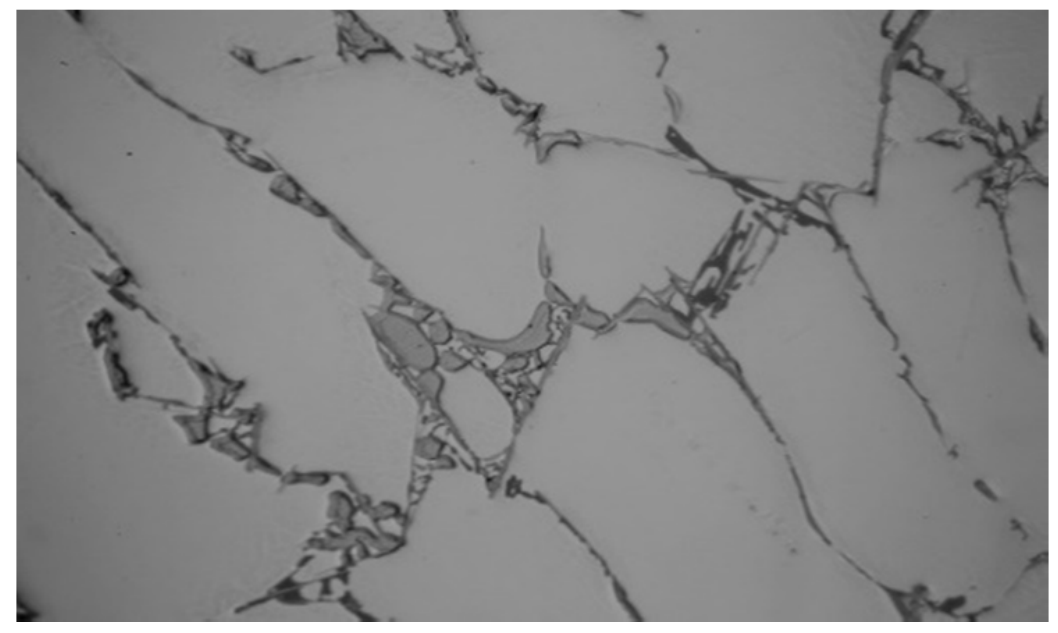

Figure 14. SEM image of Fe-34Mn-10Al-0.76C composite at PMF $=100 \mathrm{v}(\mathrm{x} 400)$

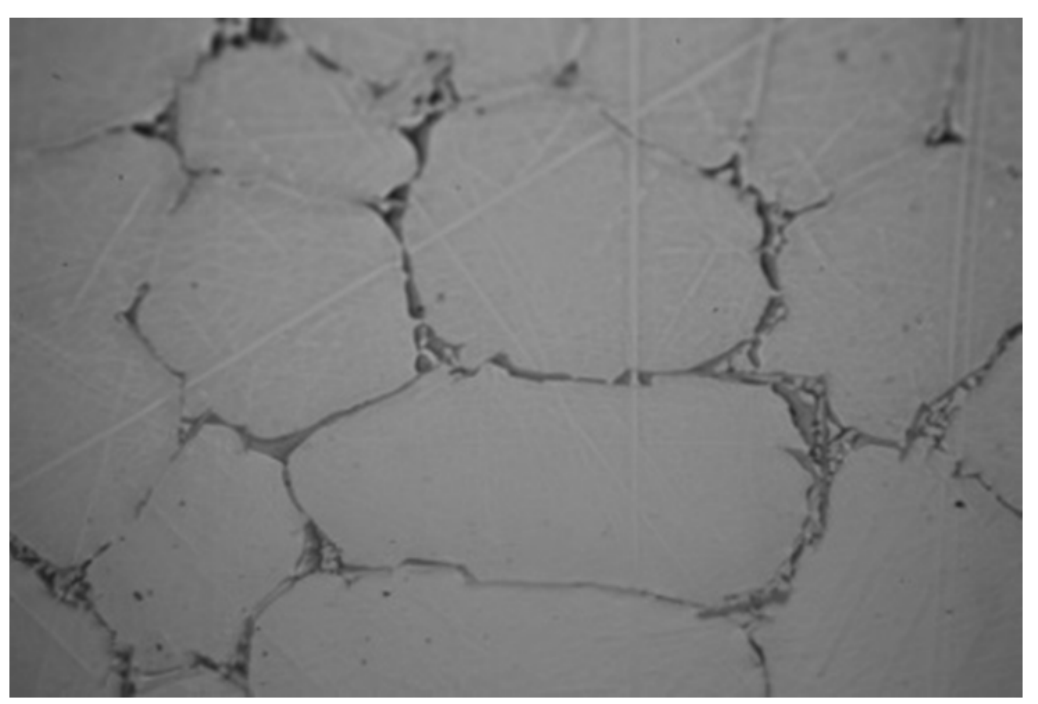

Figure 15. SEM image of Fe-34Mn-10Al-0.76C composite at PMF $=160 \mathrm{v}(\mathrm{x} 400)$. 
The laboratorial tests executed on the three samples composed of Fe-34Mn-10Al-0.76C composite permitted plotting S-N curves for every specimen. It then investigated that, raising the voltage of PMF led to an observable decline on the $(\mathrm{m})$ value until reaching 100 voltages and a noticeable increase has noted after this value. Therefore, raising voltage of PMF to $100 \mathrm{v}$ predicted to enhance the fatigue resistance of the material. The following Figure (16) shows the S-N curves for the three studied samples made of Fe-34Mn-10Al-0.76C steel alloy.

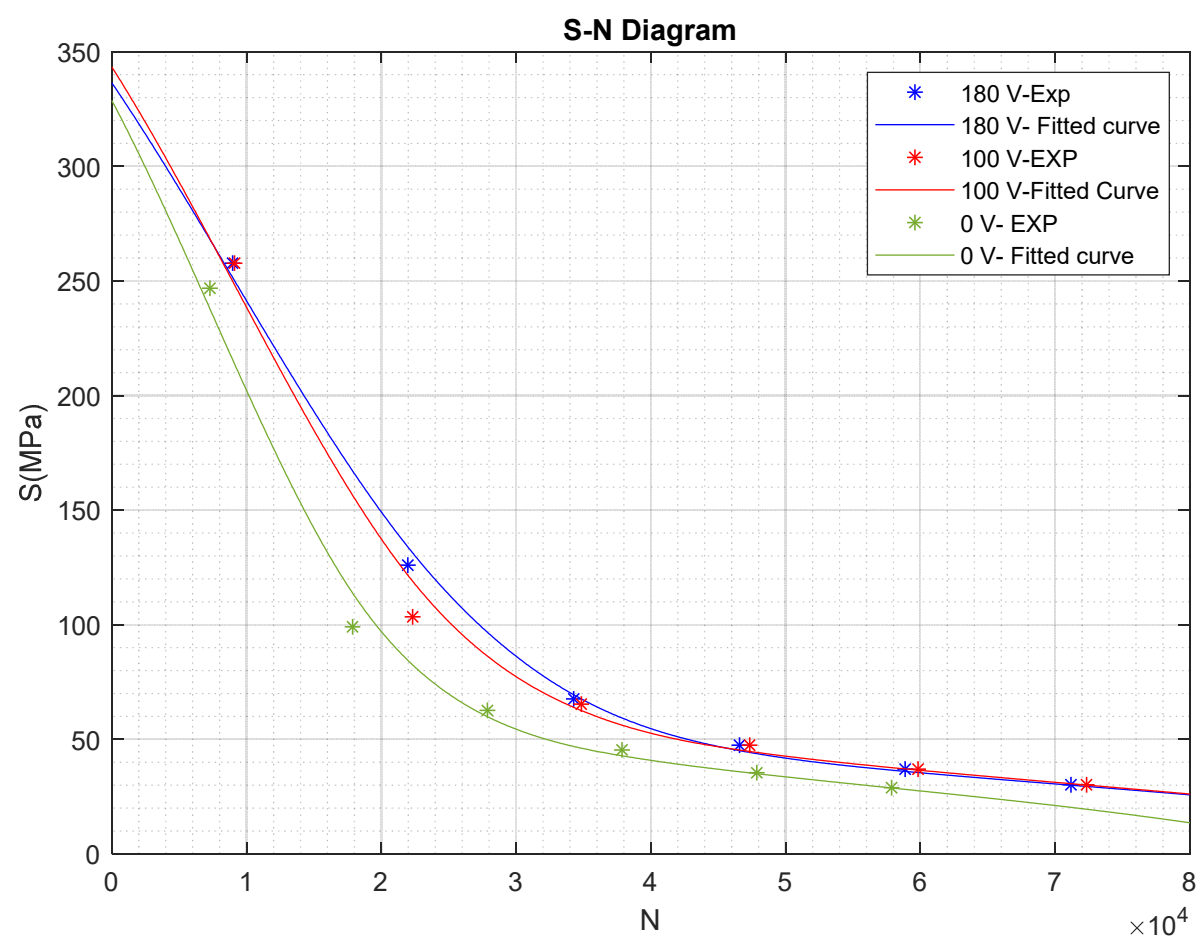

Figure 16. S-N curves for the three studied samples made of Fe-34Mn-10Al-0.76C steel alloy

A nonlinear increment in the m-1 plot established to been achieved upon raising the magnitude of PMF voltage. Three test specimens then researched to determine the fatigue life span for varying blade thicknesses. Achieved outputs that illustrated as follows;

Concerning the initial specimen, achieved outcomes permit the prediction that; raising the blade thickness improved the fatigue lifespan. Therefore, adjustment in the blade thickness would lead to an increase in its weight and consequently lowering the efficiency of the tidal turbine. Figure (17) illustrates graphically the interaction between the predicted blade fatigue lifetime and their blade thicknesses. Maximizing of the blade thickness based on the required working lifespan of the tidal turbine and it is essential for achieving a smooth and effective operation. 


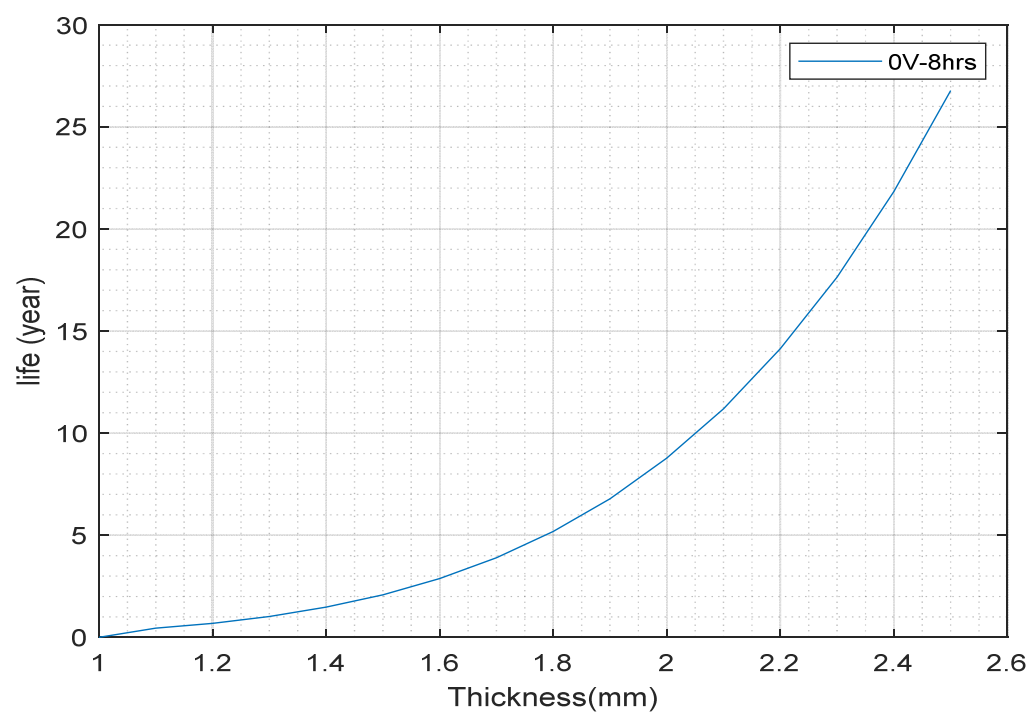

Figure 17. A graph of fatigue life of the blade made of Fe-34Mn-10Al-0.76C and treated using PMF $(0 \mathrm{v})$

Excessive working of the tidal turbine is not estimated to be effective enough although the noticeable rise in the turbine's generated power. Three different periods, which imitated using a similar scientific technique and the outcomes illustrated in the Figure (18). It was investigated that, raising the working hours of the tidal turbine causing a drastic decline in the fatigue life of the tidal turbine for a similar thickness.

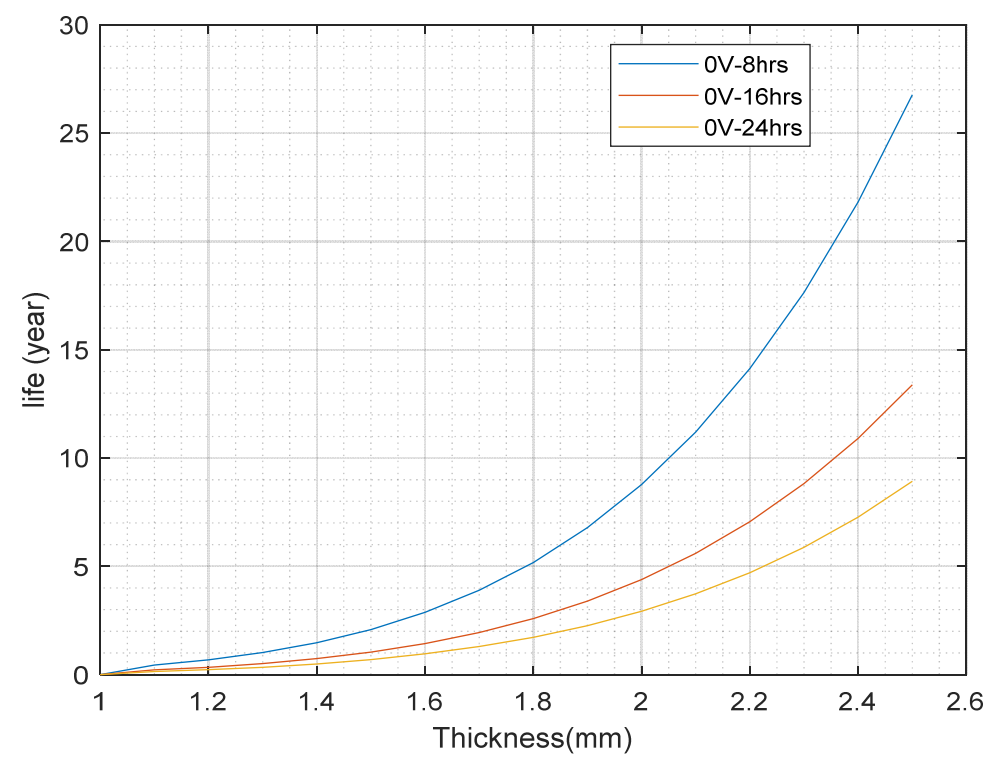

Figure 18. A graphical illustration of blade thickness against fatigue lifespan at different working hours with PMF

$(0 \mathrm{v})$

Regarding the second specimen, similar scientific techniques then followed and the collected outcomes showed that; raising the thickness of the blade consequently raised the fatigue life of the turbine. Actually, it is greatly predictable to observe a rise in the fatigue life because of the increased blade thickness. The rate of increase estimated to been adjusted because of subjecting the material to a PMF at a voltage of around $100 \mathrm{~V}$. The results as shown in Figure (20) illustrates the relationship of the predicted fatigue life and the thickness of tidal blades. 


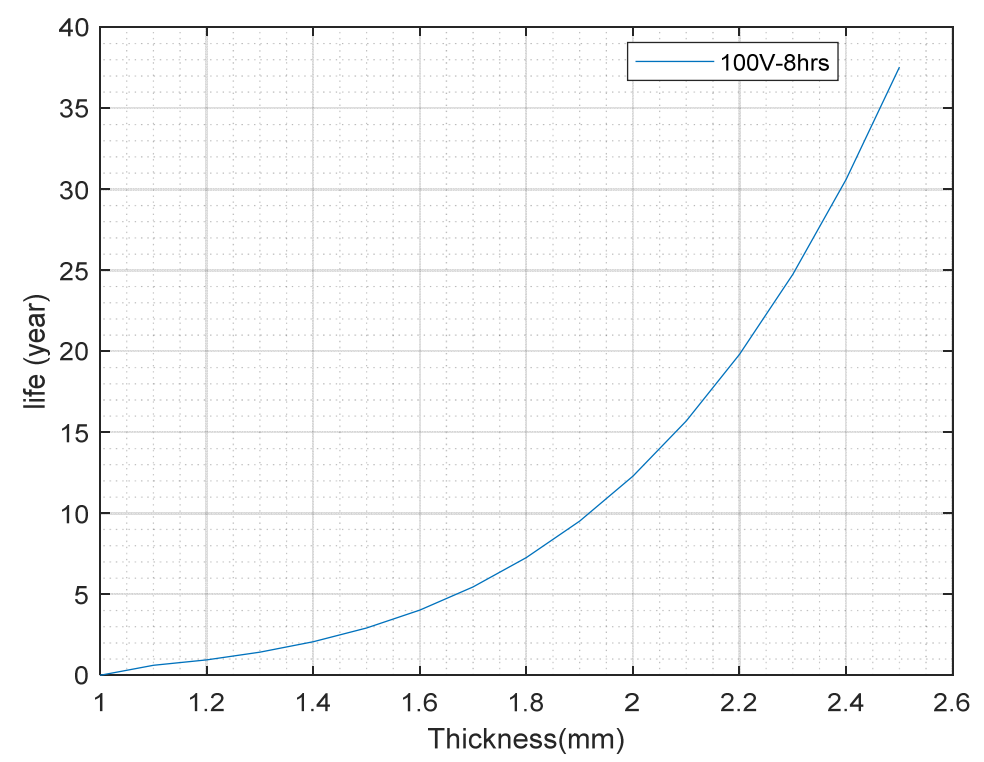

Figure 19. A graph of fatigue life of the blade made of Fe-34Mn-10Al-0.76C and treated using PMF (100 v)

It was evident that, raising the working hours of the tidal turbine leads to an increased cyclic stress causing a drastic decline in the fatigue life of the tidal turbine for a similar thickness.

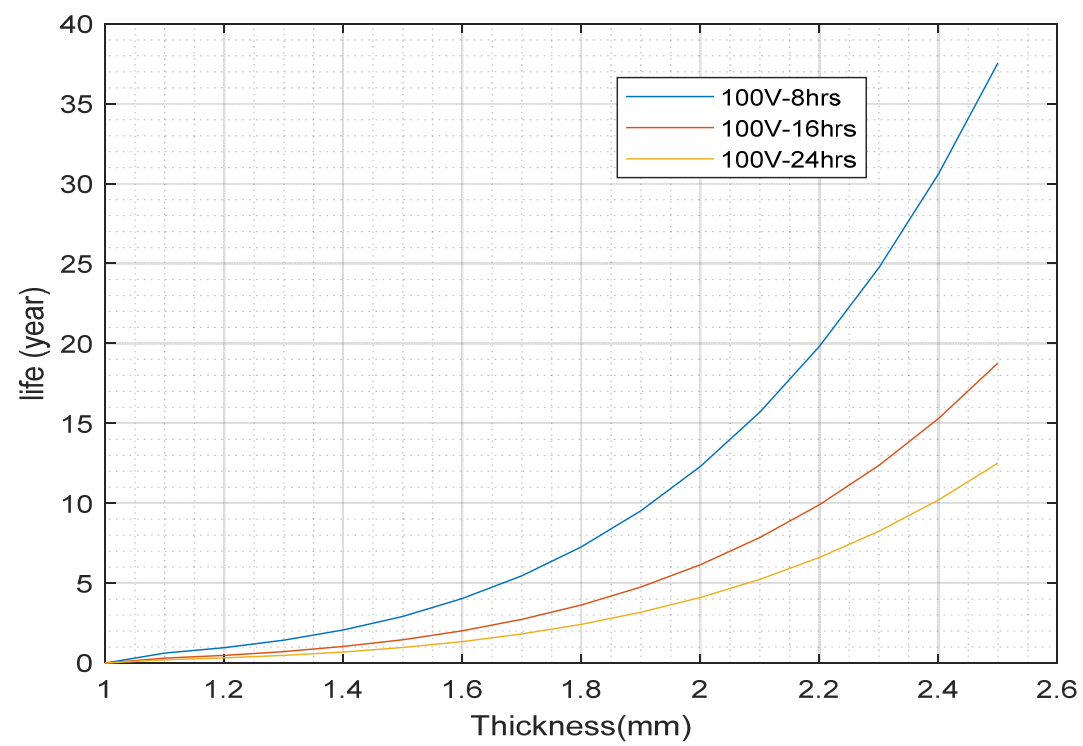

Figure 20. A graphical representation of fatigue life against blade thicknesses at different working periods with PMF (100 V)

The Similar scientific techniques then followed for the third researched sample with PMF at a voltage of $160 \mathrm{~V}$. Attained outcomes illustrated in Figure (21) exhibited a rise in the blade life span because of the increased blade thickness. However, the increase rate estimated to change because the material had subjected to a PMF at a voltage of $160 \mathrm{~V}$. 


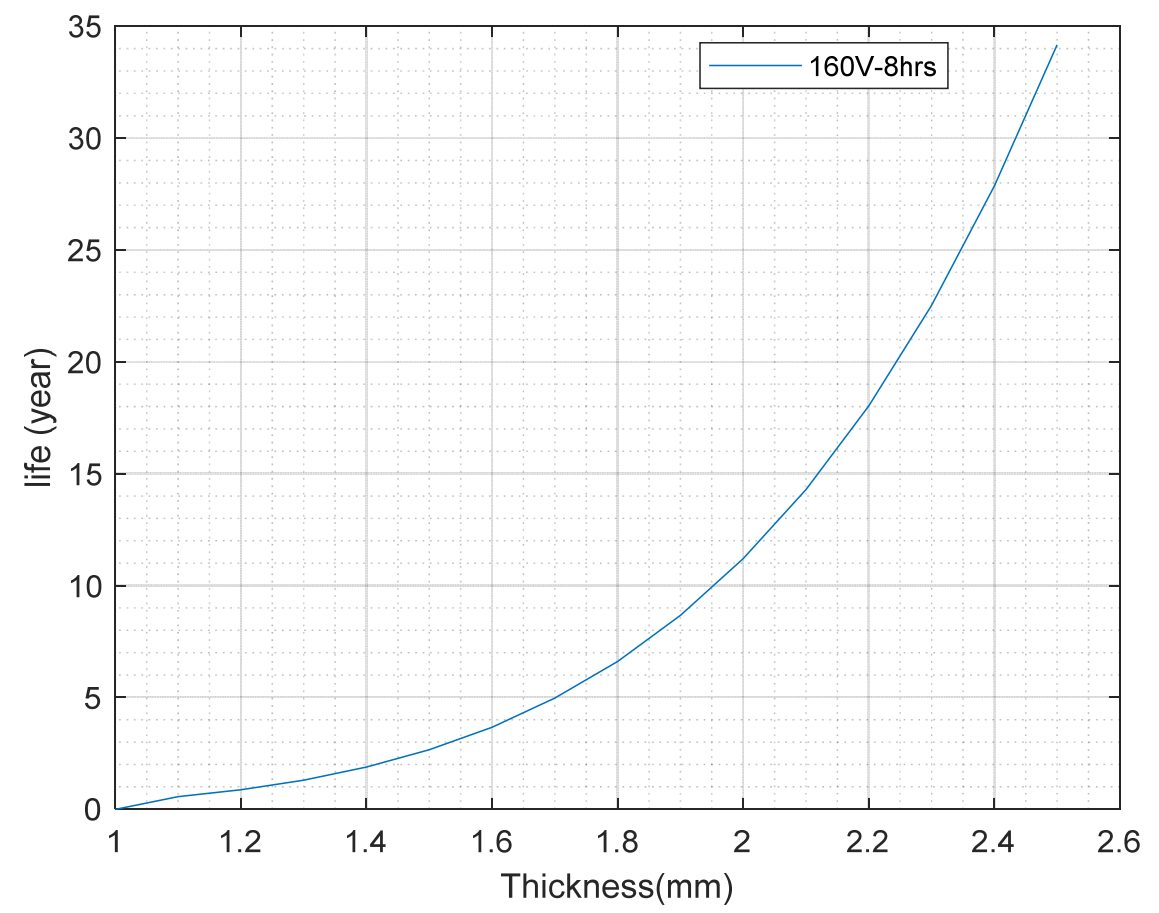

Figure 21. A graph of fatigue life of the blade made of Fe-34Mn-10Al-0.76C and treated using PMF $(160 \mathrm{v})$

Three periods were earlier imitated using similar scientific techniques and outcomes shown in Figure (22). It then investigated that, raising the working periods of the tidal turbine causes an increased cyclic stress causing a drastic decline in the fatigue lifespan of the tidal turbine for a similar researched thickness.

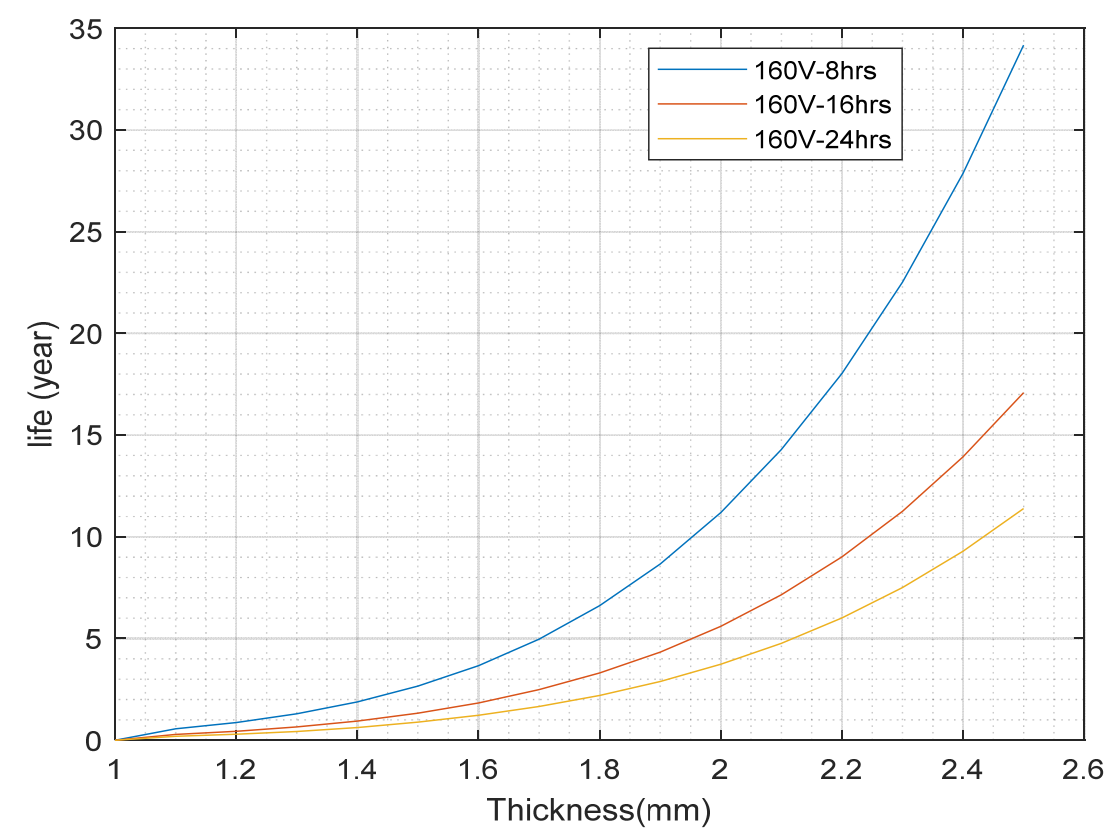

Figure 22. A graphical representation of fatigue life against blade thicknesses at different working periods with PMF (160 V) 


\section{Discussion}

Tidal turbines are equipment that specifically designed to transform the kinetic energy possessed by a moving fluid to electricity. This conversion needs aforementioned knowledge on many factors and knowing the major sources of breakages to avoid them with the intention of ensuring smooth and effective operation. Material used to manufacture turbine blades is an important factor that enables the wanted performances of the constructed tidal turbine to be achieved. Tidal turbines are not cheap and the guarantee to achieve its optimal lifespan is important in order to evade unwanted economic disadvantages. The major mechanical failures that should extensively researched is fatigue, which caused by the cyclic stress executed on the blades because of the intensity of turbulence that keeps changing with time. Fatigue failure had expressed mathematically; the major source of complexity based on the large quantities of data of the thrust loadings executed on the blades. Rainflow technique simplified the handling of such data by rearranging them as per their peaks. This aided greatly in estimating the fatigue lifespan of the tidal blade made of Fe-34Mn-10Al-0.76C steel alloy. The effectiveness of a fabric can improved when treated by subjecting to PMF, which refines its microstructure leading to improved mechanical features. This research estimated the fatigue life time of three similar tidal turbines made of similar material treated at varying voltages of $0 \mathrm{~V}, 100 \mathrm{~V}$ and $160 \mathrm{~V}$. Attained outcomes showed that, the treated material at a voltage of $100 \mathrm{~V}$ is estimated to provide higher fatigue lifespan for similar operating and environmental parameters together with the blade thickness.

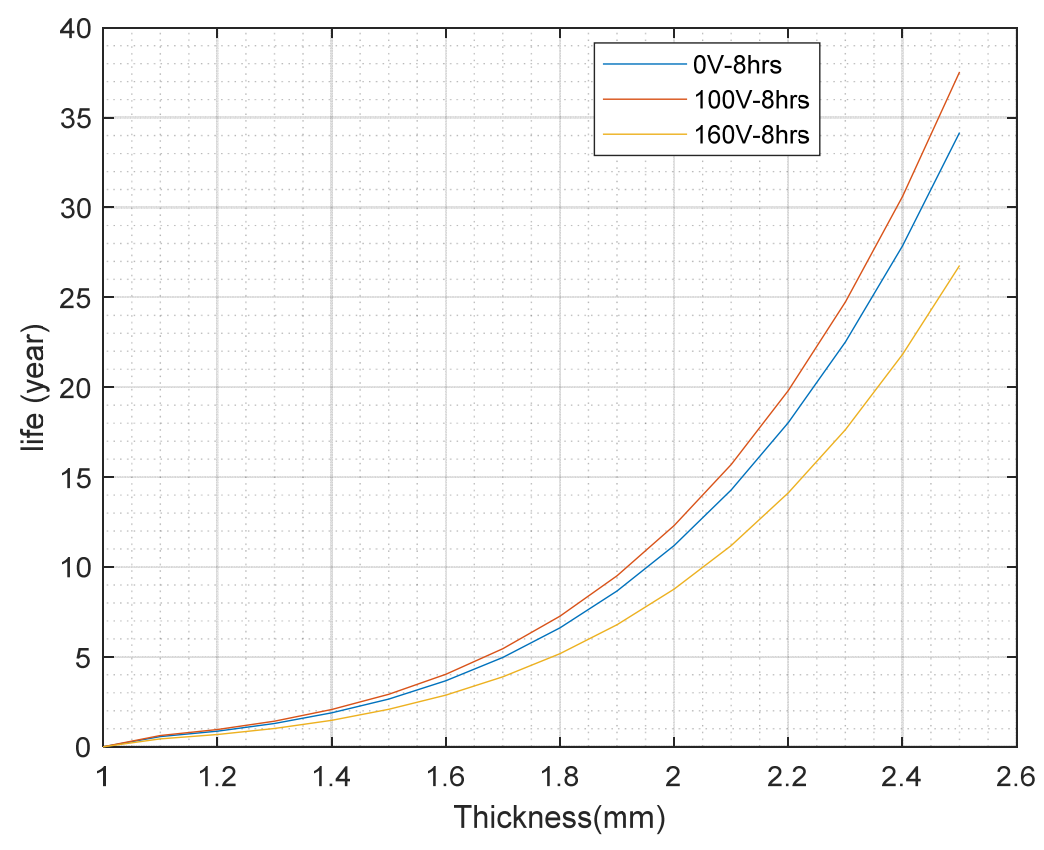

Figure 23. Effect of PMF voltage on the fatigue lifespan of the tidal turbine for different blade thicknesses

The specified number of hours that a tidal turbine designed to work within is crucial had established at the initial design phases. Mathematical expression of fatigue lifespan of the researched tidal turbine showed a noticeable decline in its lifespan while raising its working hours at constant thickness. The working hours of a blade must be maximized depending on the working and environmental conditions that the tidal turbine subjected to. This can be attained by predicting the required electrical output depending on the electrical demand needed to be satisfied. Blade thickness is desired be maximized to increase the mechanical safety, but increasing the blade thickness would increase the weight of the blade. Actually, the aforementioned scenario is not required since increasing the weight of the blade increases power losses in the energy conversion process.

\section{Conclusions}

Constructing a tidal blade to work effectively and smoothly is a complex process. Many parameters should be considered while designing it to allow in estimating its mechanical breakage and lifespan. This researched investigated the fatigue mechanism of a tidal turbine working in harsh environmental conditions to enable 
describing the major factors that affect performance and lifespan of the turbine. Lifespan of a tidal turbine influenced by blade thickness, cyclic stress originated from the seasonal changes of thrust loadings, working hours, installation depth, probability of a collision to occur, corrosion and the geographical location of the turbine. Among all these factors, this research examined the effect of a material subjected to PMF on the turbine lifespan for various blade thickness as well as different working hours. With the objective of lowering the complexity levels of the research, cyclic thrust loss executed on every blade had been normalised and examined by the Rainflow technique. Three specimens were studied to examine the PMF effect on blade performance and the collected outcomes illustrated that, the highest fatigue lifetime is to be achieved by treating Fe-34Mn-10Al-0.76C steel alloy with PMF (100 v). Increasing voltage would result in a lower performance and unnecessary economic losses.

\section{Conflict of Interests}

The authors declare that there is no conflict of interests regarding the publication of this paper.

\section{References}

Andro A. E. Sidhom, Saad A. A. Sayed, Soheir A. R. Naga. (2017). The influence of magnetic field on the mechanical properties \& microstructure of plain carbon steel. Materials Science \& Engineering A, 682, 636-639. https://doi.org/10.1016/j.msea.2016.11.083

Angelo, L., Danao, L., Abuan, B., \& Howell, R. (2016). Design Analysis of a Horizontal Axis Tidal Turbine. . Asian Wave and Tidal Conference 2016.

Baig, K. S., \& Yousaf, M. (2017). Coal Fired Power Plants: Emission Problems and Controlling Techniques. Journal of Earth Science \& Climatic Change, 08(07), 1-9. https://doi.org/10.4172/2157-7617.1000404

Browne, M., Allen, J., Nemoto, T., Patier, D., \& Visser, J. (2012). Reducing Social and Environmental Impacts of Urban Freight Transport: A Review of Some Major Cities. Procedia-Social and Behavioral Sciences, 39, 19-33. https://doi.org/10.1016/j.sbspro.2012.03.088

Cada, G. F. (1997). Shaken, Not Stirred: The Recipe for a Fish-Friendly Turbine. American Society of Civil Engineers, 5(1), 374-382.

Chen, S. P., Rana, R., Haldar, A., \& Ray, R. (2017). Current state of Fe-Mn-Al-C low density steels. Progress in Materials Science., 89, 345-391. https://doi.org/10.1016/j.pmatsci.2017.05.002

Gant, S., \& Stallard, T. (2008). Modelling a Tidal Turbine in Unsteady Flow. Proceedings of the International Offshore and Polar Engineering Conference (p. 15). Manchester, UK.

Giacovazzo, C., Monaco, H. L., Viterbo, D., Scordari, F., Gilli, G., Zanotti, G., \& Catti, M. (1992). Fundamentals of Crystallography (International Union of Crystallography Texts on Crystallography). Oxford University Press.

Hulse, M., Cronin, J., \& Tupper, M. (2011). Advanced Composite Materials for Tidal Turbine Blades. In Materials Challenges in Alternative and Renewable Energy: Ceramic Transactions (pp. 279-287). https://doi.org/10.1002/9781118019467.ch28

Humphreys, E. S., Warren, P. J., \& Cerezo, A. (1998). Characterisation of a rapidly solidified Al-V-Fe alloy. Materials Science and Engineering: A, 250(1), 158-163. https://doi.org/10.1016/S0921-5093(98)00553-X

IRENA. (2020). Ocean Energy: Technology Readiness, Patents, Deployment Status And Outlook. Retrieved May 2020, 08, from https://www.irena.org/-/media/Files/IRENA/Agency/Publication/2014/IRENA_Ocean_Energy_report_2014 .pdf

Jaksic, V., Wallace, F., \& O'Bradaigh, C. (2017). Upscaling of Tidal Turbine Blades: Glass or Carbon Fibre Reinforced Polymers?. 12th European Wave and Tidal Energy Conference (EWTEC).

Jha, S., CENSIS, \& UK, The. (2016). Tidal Turbine Collision Detection-Requirements Report. Researchgate.

Kartikasari, R., Wijaya, A., Iskandar, A., Subardi, S., \& Triyono, T. (2019). Mechanical properties and corrosion resistance of grinding ball Fe-xMn10Al-1.25C alloys. Journal of Physics Conference Series, 1375. https://doi.org/10.1088/1742-6596/1375/1/012076

Li, Y. J., Tao, W. Z., \& Yang, Y. S. (2012). Grain refinement of Al-Cu alloy in low voltage pulsed magnetic field.

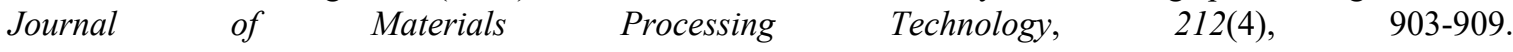
https://doi.org/10.1016/j.jmatprotec.2011.11.018 
Limon, S., Hoeppner, D., Clark, P., \& Komorowski, J. (2016). What Do Pipelines and Airplanes Have in Common? 11th International Pipeline Conference. Alberta, Canada. https://doi.org/10.1115/IPC2016-64451

Lossent, J., Lejart, M., Folegot, T., Clorennec, D., Di Iorio, L., \& Gervaise, C. (2018). Underwater operational noise level emitted by a tidal current turbine and its potential impact on marine fauna. Marine Pollution Bulletin, 131. https://doi.org/10.1016/j.marpolbul.2018.03.024

Milne, I. (2013). An experimental investigation of turbulence and unsteady loading on tidal turbines (Doctoral dissertation, University of Auckland). Researchgate.

Murray, R. E., Nevalainen, T., Gracie-Orr, K., Doman, D. A., Pegg, M. J., \& Johnstone, C. M. (2016). Passively adaptive tidal turbine blades: Design tool development and initial verification. International Journal of Marine Energy, 14, 101-124. https://doi.org/10.1016/j.jome.2016.02.001

Shadman, M., Silva, C., Faller, D., Wu, Z., de Freitas Assad, L. P., Landau, L., ... \& Estefen, S. F. (2019). Ocean renewable energy potential, technology, and deployments: a case study of Brazil. Energies, 12(19), 3658. https://doi.org/10.3390/en12193658

Stephens, E., Ross, I. L., Mussgnug, J. H., Wagner, L. D., Borowitzka, M. A., Posten, C., ... \& Hankamer, B. (2010). Future prospects of microalgal biofuel production systems. Trends in plant science, 15(10), 554-564. https://doi.org/10.1016/j.tplants.2010.06.003

Val, D. V., Yurchenko, D. V., \& Chernin, L. (2012). Effects of Extreme Loading and Fatigue on Reliability of Tidal Stream Turbine Blades. In 1st Asian Wave and Tidal Energy Conference.

Zhu, F. W., Ding, L., Huang, B., Bao, M., \& Liu, J. T. (2020). Blade design and optimization of a horizontal axis tidal turbine. Ocean Engineering, 195, 106652. https://doi.org/10.1016/j.oceaneng.2019.106652

\section{Copyrights}

Copyright for this article is retained by the author(s), with first publication rights granted to the journal.

This is an open-access article distributed under the terms and conditions of the Creative Commons Attribution license (http://creativecommons.org/licenses/by/4.0/). 